\title{
Using the Sun to find Home
}

THE ability of a pigeon to find its way home from any direction over unfamiliar territory implies that the bird can do more than simply maintain a constant compass direction. It implies that the bird in some way knows where it is in relation to its home loft. How this is achieved is still completely unknown.

One of the few theories to explain this ability is the Sun navigation hypothesis of G. V. T. Matthews (for example, J. Exp. Biol., 28, 508 ; 1951). An important part of this theory concerns how the birds know whether they have been transported to the north or to the south of their home. Matthews proposed that they did this by remembering the noon altitude of the Sun at their home loft and then comparing it with that of the Sun where they were released (if it happened not to be noon when they were released, the birds were held to observe the Sun for a short time and then to extrapolate its arc to obtain the noon position). If the noon position of the Sun were lower in the sky than it had been at their home, the birds would know that they had been moved northwards ; if it were higher, they had been displaced southwards.

Recent experiments have cast doubt on the ability of birds to obtain information about latitude displacements in this way. Walcott and Michener, for example (J. Exp. Biol., 54, 291 ; 1971), attempted to delude pigeons about the noon altitude of their home Sun by allowing them to see the Sun only after it had been deflected off a mirror so that it was too low or too high in the sky. If the birds were behaving in the way that Matthews suggested, they should then have had a false picture of what the home Sun looked like and should therefore have miscalculated how far north or south of home they were when moved to a strange place. The navigational abilities of these pigeons were not affected, however (possibly because they had remembered the true arc of the home Sun before the mirror manipulations began).

In a recent issue of Nature $\mathbf{( 2 3 7}$ 405 ; 1972) A. Whiten, of the University of Bristol, provides convincing evidence that pigeons can make use of the Sun to give them information about their latitude. Pigeons were confined in a box and rewarded for pecking at a key when pointing towards home but not when pointing away from it. Box and pigeons were transported to three widely separated sites and it was found that they could indeed tell which direction they were facing. They could easily discriminate between "away from home" and "towards home", even though no landmarks were visible and other directional cues, apart from the Sun, were excluded. When the apparent position of this Sun was altered with a periscope, the birds believed this false Sun and pecked when, according to this reflected Sun, they were pointing homewards. When they could not see the Sun at all, the discrimination failed completely. They showed the same ability in the laboratory with an artificial sun moving across a plastic dome.

The question of how birds know whether they have been displaced to the north or to the south is still open. But this new work at least shows that birds can use the Sun to navigate.From our Animal Behaviour Correspondent.

\section{PROSTAGLANDINS \\ Promise but no Miracles}

from a Correspondent

EXCITEMENT about the potential of prostaglandins as wonder drugs for abortion and contraception should subside to a more modest hope for favourable future developments in the wake of a symposium held on June 12-14. During these three days the results of two years of clinical trials were exposed to the critical view of an international gathering of people who have been assessing the efficacy of these drugs in human reproduction.

The sixty scientists-only six of them women in spite of the obvious female bias of the work reported-were guests of the Upjohn Company in the luxurious surroundings of Brook Lodge in Augusta, Michigan. The company's interest in prostaglandins began fifteen years ago, and is manifest in the acknowledgments of grateful researchers whose publications conclude with thanks to Dr J. E. Pike of the Up- john Co. for the generous supply of prostaglandins.

The profusion of such acknowledgments is evidence of the enterprise of Upjohn in setting up a research programme when prostaglandins were unglamorous substances known to cause muscle to contract. The Upjohn team had worked out two methods for synthesizing prostaglandins by 1966 , one involving the use of seminal vesicles, the other being a total synthesis method. This large group of 20-carbon carboxylic fatty acids was discovered in 1930 by two New York gynaecologists, Raphael Kurzrok and Charles C. Lieb, and named by Ulf von Euler of the Karolinska Institute in Stockholm. At the Brook Lodge symposium, which coincided with Upjohn's applications to market the first prostaglandins in several countries, one of von Euler's colleagues, Sune Bergström, was a guest of honour.

The first day was packed with reports from groups that have been using prostaglandins $E_{2}$ and $F_{2 \alpha}$ to induce labour in women whose pregnancies have reached term and who need, for some reason, to be delivered immediately. The pituitary hormone oxytocin is used intravenously as a routine means of inducing labour, and results so far with prostaglandins do not indicate any definite advantage by this route of administration. Given orally, however, prostaglandins seem to have a potential advantage.

In a double blind comparison involving 169 women, reported by Dr G. G. Anderson ((Yale University School of Medicine), prostaglandins $\mathrm{E}_{2}$ and $\mathrm{F}_{2 \alpha}$ administered intravenously were equally effective inducers of labour as oxytocin. Anderson and his colleagues found that the prostaglandins seemed to be as safe as oxytocin, and reported some innocuous hypertonus as the only side effect. Dr A. I. Sherman (Sinai Hospital, Detroit) reported similar results from a double blind study. His group found that prostaglandin $\mathrm{F}_{2 \alpha}$ compared very favourably with oxytocin for the induction of labour at term.

Dr W. N. Spellacy (University of Miami) sounded a note of warning when reporting his own double blind intravenous study with oxytocin and prostaglandin $\mathrm{F}_{2 a}$ used to induce labour in 222 women. With prostaglandin he found a greater proportion of maternal complications in the form of uterine hypertonus, hot flushes and infusion vein phlebitis. There was also a greater need to perform Caesarian sections in these women. Spellacy recommended 